\title{
PRIMARY STRUCTURE OF CARBOXYPEPTIDASE II FROM MALTED BARLEY
}

\author{
by \\ STEEN BECH SØRENSEN, IB SVENDSEN and KLAUS BREDDAM
}

Department of Chemistry, Carlsberg Laboratory, Gamle Carlsberg Vej 10, DK-2500 Copenhagen Valby

Keywords: Amino acid sequence, sequence homology, serine carboxypeptidase

\begin{abstract}
The primary structure of malt carboxypeptidase II has been determined. The enzyme is a dimer where each monomer is composed of two peptide chains, an A- and a B-chain, linked by disulphide bridges. The B-chain exists in two forms, both $\mathrm{N}$-terminally blocked, which differ in position 38 and 39 , one form containing $\mathrm{Ala}^{38}-\mathrm{Thr}^{39}$, the other containing $\mathrm{Thr}^{38}$-Asn ${ }^{39}$ with carbohydrate attached to the asparagine side-chain. Fragments of the $\mathrm{A}$ - and B-chains were obtained by chemical cleavages with either cyanogen bromide, hydroxylamine or iodosobenzoic acid and by enzymatic cleavages with either trypsin or S. aureus V8 protease, sequenced and aligned to give the total sequence.

The A- and B-chains contain 260 and 159 amino acid residues, respectively. Glycosylated asparagines are found in positions 114, 125 and 257 of the A-chain, and positions 28, 34, 39 and 159 of the B-chain. Position 39 of the B-chain is only partially glycosylated (see above). Alignment of the sequence of the A-chain with the N-terminal part of carboxypeptidase Y revealed $28 \%$ homology. Similarly, the B-chain showed $21 \%$ homology with the C-terminal part of carboxypeptidase Y. The homology between malt carboxypeptidases I and II is $40 \%$ for the A-chains and $30 \%$ for the B-chains. The corresponding homologies between malt carboxypeptidase II and wheat carboxypeptidase II are $95 \%$ and $96 \%$, respectively. No homology was observed with other proteins by a computer search of a sequence data base provided by the National Biomedical Research Foundation. A region of the A-chain was identical to the region around the essential seryl residue in position 146 of carboxypeptidase Y.
\end{abstract}

\section{INTRODUCTION}

According to MiKOLA (14), germinating barley contains five serine carboxypeptidases of complementary specificities and three of these, carboxypeptidase I, II and III have been isolated and characterised in this laboratory $(4,5,6)$. These enzymes in combination with endopeptidases, very effectively produce free amino acids during germination by cleavage of reserve proteins in the endosperm. We have previously reported the sequence of malt carboxypeptidase
I (18). This enzyme consists, like a number of serine carboxypeptidases from higher plants (2), of two identical subunits, each composed of two peptide chains, cross-linked by disulphide bridges (6). The amino acid sequence is homologous with that of carboxypeptidase $Y$ from yeast $(3,13,17)$, especially in the region around the reactive seryl residue. However, carboxypeptidase $Y$ consists of a single peptide chain. In the present report, the primary structure of malt carboxypeptidase II has been determined, and it

Abbreviations: CABS-Sepharose $=[\mathrm{N}-(\varepsilon$-aminocaproyl $)$-p-amino-benzyl $]$ succinyl-Sepharose 4B; $\mathrm{DPCC}=$ diphenylcarbamyl chloride; EDTA = ethylenediaminetetraacetic acid, disodium salt; HPLC $=$ high pressure liquid chromatography; PTH = phenylthiohydantoin; TFA = trifluoroacetic acid. 
is demonstrated that the sequence of this enzyme is almost identical with that of wheat carboxypeptidase II and homologous with that of malt carboxypeptidase I and carboxypeptidase $\mathrm{Y}$.

\section{MATERIALS AND METHODS}

\subsection{Materials}

Malt carboxypeptidase II was prepared as previously described (6) from malted Gula barley (obtained from the Carlsberg Breweries, Denmark) by affinity chromatography on CABS-Sepharose.

Bio-Gels P-200, P-60, P-30 and P-6 were from Bio-Rad, USA. DPCC-treated trypsin and dithiothreitol were from Sigma, USA. S. aureus V8 protease was from Miles, USA. Carboxypeptidase $Y$ was a product of Carlsberg Biotechnology, Denmark. 2-vinylpyridine was from Janssen Chimica, Belgium. All other chemicals were analytical or HPLC-grade from Merck, W. Germany.

\subsection{Methods}

\subsubsection{Separation of peptide chains}

After reduction and alkylation with 2vinylpyridine of malt carboxypeptidase II as previously described (5), the A-chain (mol. weight 34,000 ) was separated from the B-chains (mol.weight 24,000-27,000) by gel filtration on Bio-Gel P-200 $(5.0 \times 88 \mathrm{~cm})$ equilibrated with $5 \%$ (v/v) acetic acid.

\subsubsection{Cleavage of peptide bonds}

Chemical cleavage by cyanogen bromide and hydroxylamine and enzymatic digestion with trypsin of the reduced and alkylated chains was performed as previously described (18).

Cleavage at the carboxyl group of tryptophan residues in the A-chain was performed according to the procedure described by FONTANA et al. (8). The reaction was carried out in the dark at room temperature overnight. Tyramine hydrochloride $\left(5 \mathrm{mg} \cdot \mathrm{ml}^{-1}\right)$ was included as a scavenger in the reagent which consisted of o-iodosobenzoic acid $\left(20 \mathrm{mg} \cdot \mathrm{ml}^{-1}\right)$ in $4 \mathrm{M}$-guanidine hydrochloride and $80 \%$ acetic acid.
Digestion with S. aureus V8 protease (11) was performed at $25^{\circ} \mathrm{C}$ in $0.1 \mathrm{M}$-ammonium bicarbonate and $2 \mathrm{M}$-urea at $\mathrm{pH} 7.8$. The reduced and alkylated peptide chains were dissolved in 6 M-urea and diluted with 2 volumes $0.15 \mathrm{M}$-ammonium bicarbonate $\mathrm{pH} 7.8$. Then enzyme was added and after 2-3 hours digestion the reaction was stopped by addition of TFA.

\subsubsection{C-terminal sequence determination}

$\mathrm{C}$-terminal sequences of the entire A-chain and the CB4 fragment of the B-chain were determined by digestion with carboxypeptidase $Y$. The following conditions were used: $0.23 \mathrm{mM}$ A-chain, 0.1 M-Mes, 1 mM-EDTA, 0.1\% SDS, pH 7.0, $2.5 \mu \mathrm{M}$ carboxypeptidase $\mathrm{Y}$ and 0.27 mM-CB4, 0.05 M-sodium acetate, $\mathrm{pH} 5.0,7.7 \mu \mathrm{M}$ carboxypeptidase $\mathrm{Y}$. Aliquots were withdrawn during the reaction, $\mathrm{pH}$ was adjusted to 2.0 by addition of $0.5 \mathrm{M}-\mathrm{HCl}$ and the aliquots were applied directly to a Durrum D500 amino acid analyzer.

\subsubsection{Separation of peptide fragments}

Separation and purification of large peptide fragments were performed by gel filtration through Bio-Gel P-60 or P-30 in $10-30 \%(v / v)$ acetic acid. Purification of small peptides was performed by reverse phase HPLC using equipment from Waters and wide pore $\mathrm{C}_{18}$ columns i.d. $4.6 \mathrm{~mm}$ and length $25 \mathrm{~cm}$ (J.T. Baker no. RP 7104-0 or Vydac no. 218TPb). Gradient elution was performed with linear gradients of acetonitrile in $0.1 \%(\mathrm{w} / \mathrm{w})$ trifluoroacetic acid at a flow rate of $1.0 \mathrm{ml} \cdot \mathrm{min}^{-1}$. The eluate was monitored at $220 \mathrm{~nm}$ supplemented with fluorescence detection at $375 \mathrm{~nm}$ after excitation at $280 \mathrm{~nm}$, to detect tryptophan containing peptides. Inhomogeneous fractions were rechromatographed in the same system but employing a more flat and narrow gradient of acetonitrile.

\subsubsection{Amino acid sequence determinations}

Peptides were sequenced either on a Beckman model $890 \mathrm{C}$ liquid phase sequencer as previously described (12) or on an Applied Biosystems model $470 \mathrm{~A}$ gas-phase sequencer, using the 


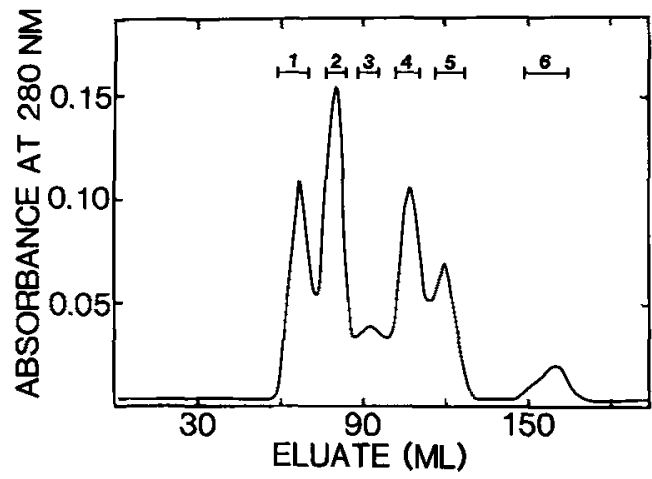

Figure 1. Separation of cyanogen bromide fragments of the A-chain ( $4 \mathrm{mg}$ ) on Bio-Gel P-60. The column $(1.6 \times 86 \mathrm{~cm})$ was eluted with $30 \%$ acetic acid at a flow rate of $7 \mathrm{ml} \cdot \mathrm{h}^{-1}$. Fractions $(1.5 \mathrm{ml})$ were pooled as indicated. Pool 6 was further purified by HPLC.

program provided by the company. The phenylthiohydantoin amino acid derivatives from the gas-phase sequencer were identified on-line by reverse phase HPLC using equipment from Applied Biosystems, while those from the liquid phase sequencer were identified with a Hewlett-Packard HPLC system using a linear gradient from 10 to $45 \%$ methanol, (16). Amino acid compositions were determined as previously described (5).

\subsubsection{Peptide nomenclature}

Peptide fragments obtained by cleavage with cyanogen bromide, hydroxylamine, iodosobenzoic acid, trypsin or $\mathrm{S}$. aureus V8 protease are designated $\mathrm{CB}, \mathrm{NG}, \mathrm{W}, \mathrm{T}$ and $\mathrm{E}$, respectively, followed by a number indicating their positions in the polypeptide chain from the $\mathrm{N}$-terminus of the protein.

\section{RESULTS}

\subsection{N-terminal sequences of $\mathbf{A}$ - and B-chains}

The A- and B-chains, as obtained by gel chromatography of the reduced and alkylated enzyme, were subjected to $\mathrm{N}$-terminal sequence determination. The A-chain was sequenced 37 cycles, while the B-chain was found to be N-terminally blocked. The blocking group was both acid and base labile. After its removal, the B-chain could be sequenced 25 cycles.

\subsection{Cyanogen bromide fragments}

According to the amino acid analysis, the A-chain of malt carboxypeptidase II contains four methionyl residues (6) corresponding to five cyanogen bromide fragments. Chromatography of the cyanogen bromide treated A-chain on Bio-Gel P-60 (Figure 1) produced six peaks. Pool 1 contained two peptides which later was demonstrated to originate from incomplete cleavage after two methionines. Pool 2 contained one peptide (CB3, 103 res.) which was sequenced 48 cycles. Pool 3 contained one peptide (CB4+5, 77 res.) originating from incomplete cleavage at $\mathrm{Met}^{248}$. Pool 4 contained CB4 (65 res.), which was sequenced 53 cycles. Pool 5 contained CB2 (58 res.) which was sequenced 25 cycles and pool 6 was found to be a mixture of the $\mathrm{N}$-terminal cyanogen bromide fragment ( $\mathrm{CBl}, 22$ res.) and the C-terminal cyanogen bromide fragment (CB5, 12 res.). After rechromatography by HPLC the complete sequence of CB5 could be determined.

Chromatography of the cyanogen bromide fragments of the B-chain on Bio-Gel P-60 yielded three peaks (Figure 2). Pool 1 contained a single peptide (CB3, 98 res.) which was se-

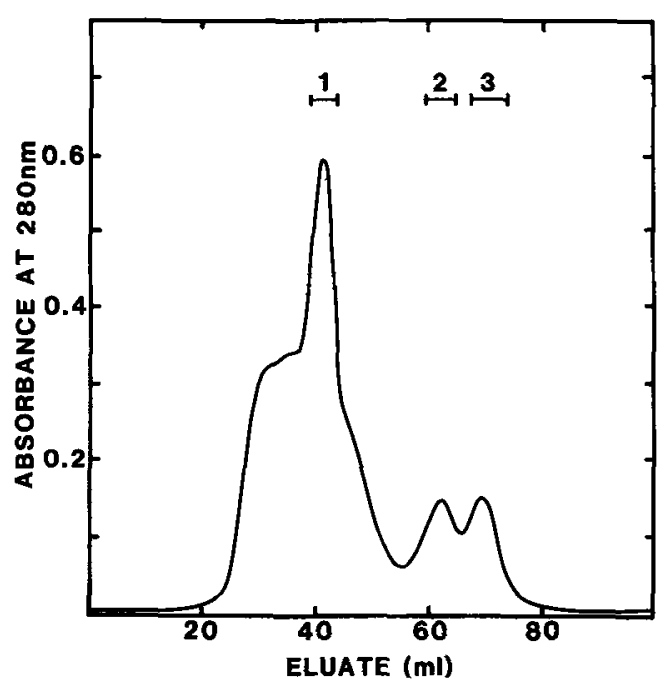

Figure 2. Separation of cyanogen bromide fragments of the B-chain $(7 \mathrm{mg}$ ) on Bio-Gel P-60. The column $(1.5 \times 88 \mathrm{~cm})$ was eluted with $30 \%$ acetic acid at a flow rate of $4 \mathrm{ml} \cdot \mathrm{h}^{-1}$. Fractions $(1.3 \mathrm{ml})$ were pooled as indicated. 


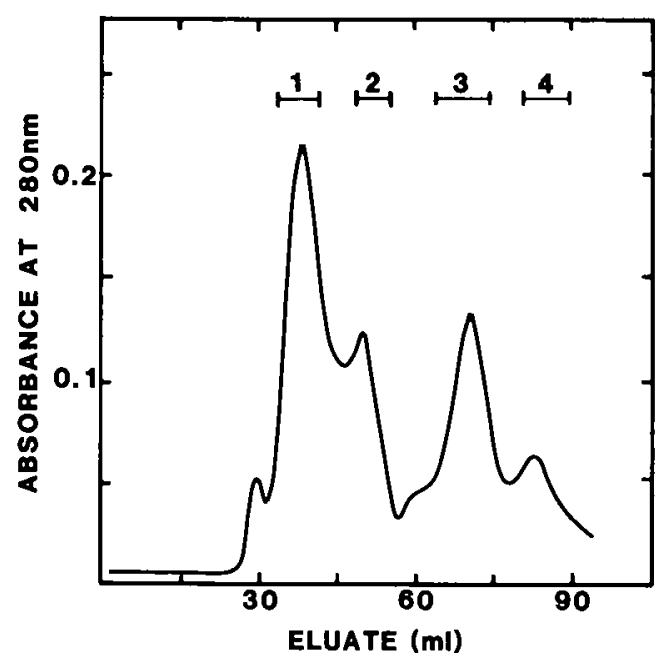

Figure 3. Separation of hydroxylamine fragments of the A-chain (5.0 mg) on Bio-Gel P-60. The column $(1.5 \times 88 \mathrm{~cm})$ was eluted with $10 \%$ acetic acid at a flow rate of $7 \mathrm{ml} \cdot \mathrm{h}^{-1}$. Fractions $(1.5 \mathrm{ml})$ were pooled as indicated.

quenced 25 cycles. Pool 2 contained CB1 (33 res.) which was sequenced 25 cycles and pool 3 contained CB2 (22 res.) which was sequenced to the end and found to be polymorphous at two positions. The $\mathrm{C}$-terminal cyanogen bromide fragment (CB4, 6 res.) could be isolated after reverse phase HPLC of the cyanogen bromide cleaved B-chain. It was sequenced 6 cycles. The C-terminal digestion with carboxypeptidase $\mathrm{Y}$ released no amino acids.

\subsection{Hydroxylamine fragments}

The fragments formed by cleavage of the A-chain with hydroxylamine could be purified by gel filtration on Bio-Gel P-60 (Figure 3). Pool 1 and 2 had identical $\mathrm{N}$-terminal sequences (NG2) indicating that the cleavage at $\mathrm{Asn}^{186}$. Gly ${ }^{187}$ was incomplete. Pool 2 was sequenced 33 cycles and provided the overlap between CB2 and CB3. Pool 3 contained NG3, the $\mathrm{N}$-terminal sequence of which was known from the sequence of CB4. Pool 4 contained the already known N-terminal peptide, Ala'-Asn ${ }^{58}$.

Cleavage of the B-chain mixture with hydroxylamine and subsequent chromatography on Bio-Gel P-60 revealed only a single peak indicat-

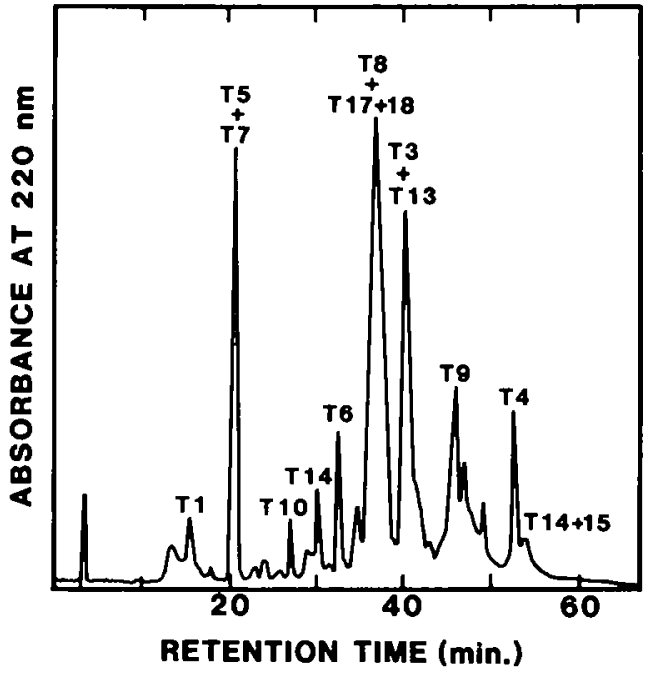

Figure 4. Fractionation of a tryptic digest of the A-chain by reverse phase HPLC using a Novapac $8 \mathrm{NV} \mathrm{C}_{18}$ column (radial pac). The column was eluted over $60 \mathrm{~min}$ with a gradient from 0 to $54 \%$ acetonitrile in $0.1 \%$ TFA at a flow rate of $1.0 \mathrm{ml} \cdot \mathrm{min}^{-1}$. The eluate was monitored at $220 \mathrm{~nm}$.

ing the absence of $\mathrm{N}-\mathrm{G}$ sequences in both forms of the B-chain.

\subsection{Tryptic peptides}

The amino acid composition of the A-chain of malt carboxypeptidase II indicated 3-4 Lys and 12 Arg residues (6), corresponding to 16-17 tryptic peptides. HPLC-chromatography of the digestion mixture revealed a complex chromatogram with fairly well resolved peaks (Figure 4). It was possible to identify several of the peptides from the amino acid analysis combined with the available sequence data. The remaining unknown peptides were sequenced as far as possible, in most cases by means of the gas-phase sequencer. Incomplete tryptic cleavages were observed between Lys $^{180}$ - Gly ${ }^{181}$ and Lys $^{217}$ $\mathrm{Asp}^{218}$. Sequencing of T4 provided the overlap between $\mathrm{CB} 2$ and NG2, while $\mathrm{T} 17+18$ gave the overlap between CB4 and CB5.

Amino acid analysis of the B-chain indicated 2 Lys and 12 Arg residues (6) consistent with 15 tryptic peptides. By HPLC-chromatography of the digestion mixture (Figure 5) several pure 


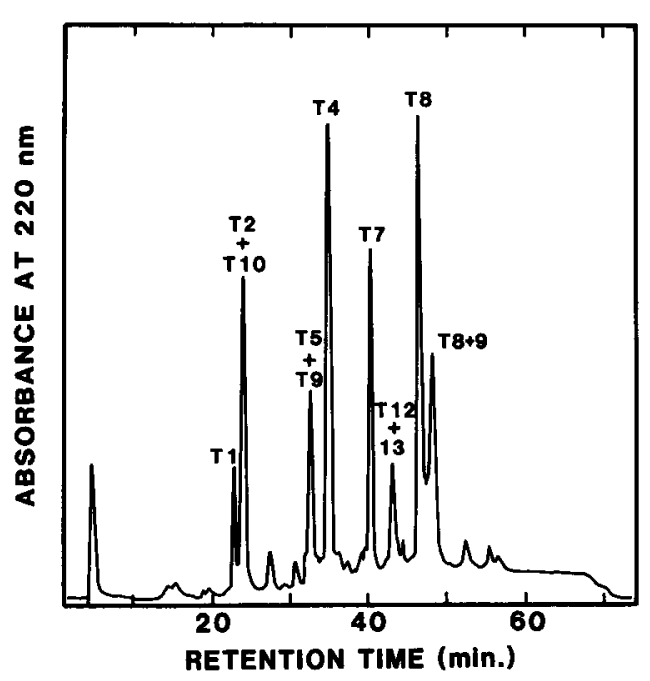

Figure 5. Fractionation of a tryptic digest of the B-chain by reverse phase HPLC using a wide pore $\mathrm{C}_{18}$ column (Bakerbond). The column was eluted over $60 \mathrm{~min}$ with a gradient from 0 to $54 \%$ acetonitrile in $0.1 \%$ TFA at a flow rate of $1.0 \mathrm{ml} \cdot \mathrm{min}^{-1}$. The eluate was monitored at $220 \mathrm{~nm}$.

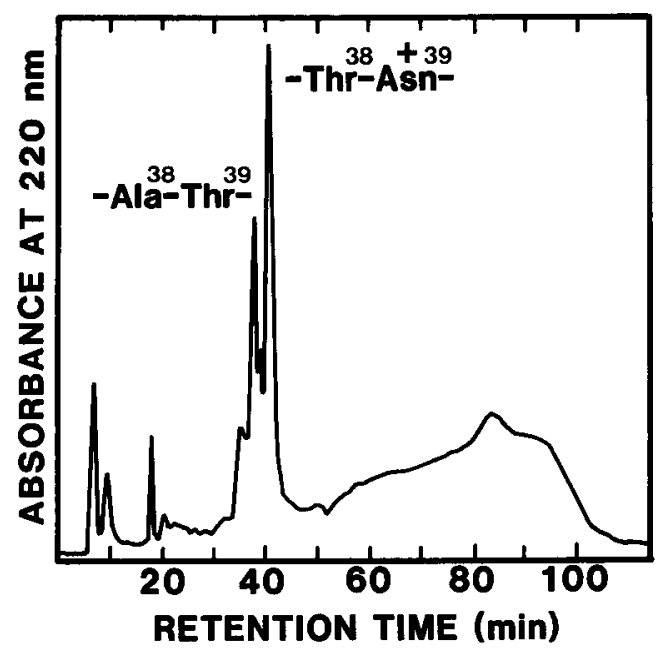

Figure 6. Rechromatography of a pool from Bio-Gel P-30 chromatography of a tryptic digest of the B-chain on a reverse phase wide pore $C_{18}$ column (Bakerbond). The column was eluted over $80 \mathrm{~min}$ with a gradient from 2 to $45 \%$ acetonitrile in $0.1 \%$ TFA at a flow rate of $0.5 \mathrm{ml} \cdot \mathrm{min}^{-1}$. The eluate was monitored at $220 \mathrm{~nm}$. fragments were obtained and rechromatography by HPLC of a fraction obtained by Bio-Gel chromatography of a tryptic digest resulted in the separation of two T4 peptides (Figure 6) which differed only at two positions. This was the only indication of polymorphism in the B-chain. The sequences of the tryptic fragments $\mathrm{T} 4$ and $\mathrm{T} 5$ provided the overlaps between $\mathrm{CB} 1$ and $\mathrm{CB} 2$ and between $\mathrm{CB} 2$ and $\mathrm{CB} 3$, respectively. Sequencing of $T 12+13$ revealed that the tryptic cleavage at Lys ${ }^{151}$ - Pro ${ }^{152}$ had been incomplete.

\subsection{S. aureus $V 8$ protease fragments}

The entire A-chain was digested with S. aureus V8 protease. The resulting fragments were separated by reverse phase HPLC (Figure 7). Sequence analysis of E13 provided the overlap

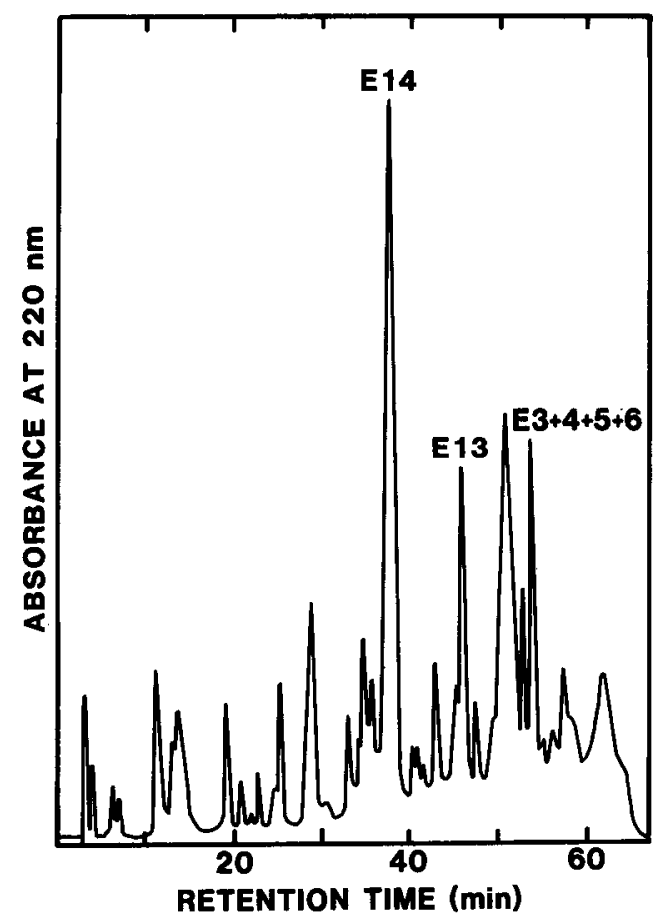

Figure 7. Separation of $S$. aureus V8 protease fragments from the A-chain by reverse phase HPLC using a wide pore $C_{18}$ column (Bakerbond). The column was eluted over $60 \mathrm{~min}$ with a linear gradient from 14 to $41 \%$ acetonitrile in $0.1 \%$ TFA at a flow rate of 1.0 $\mathrm{ml} \cdot \min ^{-1}$. The eluate was monitored at $220 \mathrm{~nm}$. 


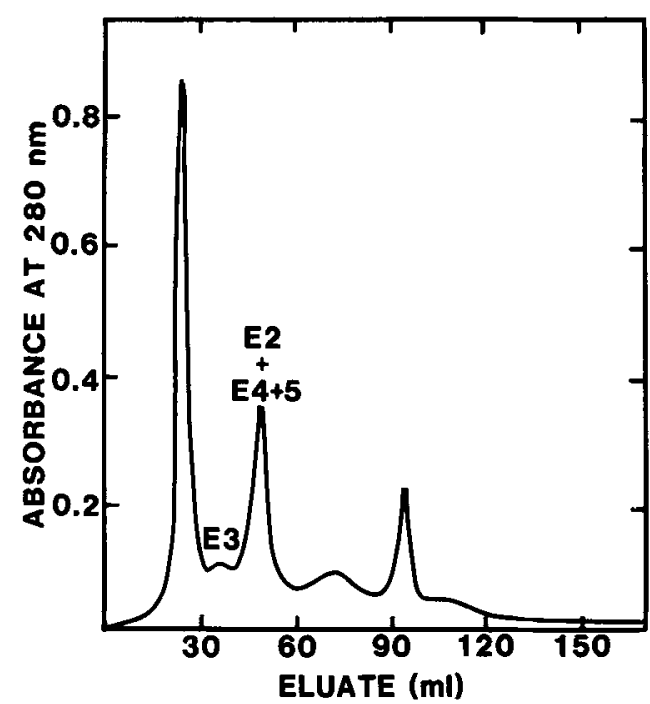

Figure 8. Separation of S. aureus V8 protease fragments of the B-chain ( $5 \mathrm{mg}$ ) on Bio-Gel P-30. The column $(1.5 \times 90 \mathrm{~cm})$ was eluted with $10 \%$ acetic acid at a flow rate of $6 \mathrm{ml} \cdot \mathrm{h}^{-1}$.

between $\mathrm{T} 13$ and $\mathrm{T} 14+15$ and hence, the position of CB4 in the chain.

The B-chain was digested with V8 protease and the fragments were separated by gel filtration on Bio-Gel P-30 (Figure 8). Sequence analysis of $\mathrm{E} 4+5$ (cleavage at $\mathrm{Glu}^{131}-\mathrm{Val}^{132}$ was incomplete) provided the overlap between $T 8$ and $\mathrm{T} 12+13$. The sequence of $\mathrm{E} 3$ secured the overlap between $\mathrm{T} 7$ and $\mathrm{T} 8$.

\subsection{Fragments obtained by cleavage with o-iodosobenzoic acid}

The entire A-chain was cleaved with iodosobenzoic acid (8) and the fragments were separated by HPLC. Sequence analysis of W4 provided the overlap between $\mathrm{T} 9$ and $\mathrm{T} 13$.

\subsection{Assignment of glycosylated asparagines}

The A-chain of malt carboxypeptidase II contains 6 glucosamine residues (6). These were assigned to three glycosylated asparagines $\left(A s n^{114}, A_{s n}^{125}\right.$ and $A s n^{257}$ ) from the absence of detectable PTH-amino acid in these positions after Edman degradation, the presence of a hydroxyamino acid two positions from the vacant position towards the C-terminal end, and finally by the amino acid analysis of T 8 and CB5 indicating the presence of glucosamine and the excess of one or two Asx as compared with the composition obtained from the sequence determined. Similarly, the B-chain was found to contain glycosylated asparagines at positions 28 , 34 and 159. Furthermore, one of the two forms of the B-chain contained a glycosylated asparagine at position 39 .

\section{DISCUSSION}

Earlier investigations (6) have shown that malt carboxypeptidase II, like wheat carboxypeptidase II (7) and malt carboxypeptidase $\mathrm{I}(5,18)$, is composed of two subunits where each subunit is constituted of two peptide chains, an A-chain and a B-chain, linked together by disulphide bridges. Determination of the amino acid sequence of serine carboxypeptidase II from barley malt revealed that the A-chain contained 260 amino acid residues (Figure 9). Earlier studies (6) indicated that the B-chain existed in two forms which differed about 3,000 daltons in molecular weight due to different contents of carbohydrate. This is supported by the present study where it is shown that the B-chain is polymorphous at positions 38 and 39: one form with the sequence $\mathrm{Thr}^{38}$-Asn ${ }^{39}$ with carbohydrate attached and the other with the sequence $\mathrm{Ala}^{38}-\mathrm{Thr}^{39}$ without carbohydrate. No evidence of polymorphism at other positions has been found. The two forms of the B-chain which contain 159 amino acid residues (Figure 10) were $\mathrm{N}$-terminally blocked. The nature of the blocking group has not been investigated but it was observed that the group was released after exposure to acidic as well as basic conditions. The presence of two forms of the B-chain indicates that barley contains at least two genes each coding for one form of the B-chain.

The amino acid compositions of the A- and $B$-chains as calculated from the sequences are in good agreement with the compositions determined by amino acid analysis (Table I). The A-chain is N-glycosylated at 3 asparagines at positions 114,125 and 257 . The glycosylation 
S.B. SøRENSEN et al.: Sequence of malt carboxypeptidase II

10

20

30

40

A G G H A A D R I V R L P G $Q$ P N-terminal

$\stackrel{\mathrm{CB} 2}{\mathrm{T3}}$

50

60

70

80

L $Q$ E A P E E A Q P A P L V L W L N G G P G C S S V A Y G A S E E L G A E R V M

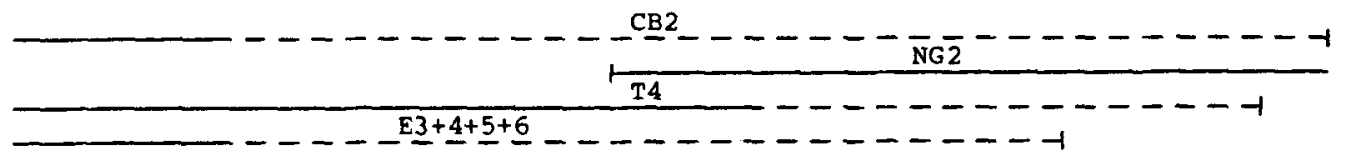

90

100

110

120

P R G A G L V L N E Y R W N K V A N V L F L D S P A G V G F S Y T N T S S D I Y

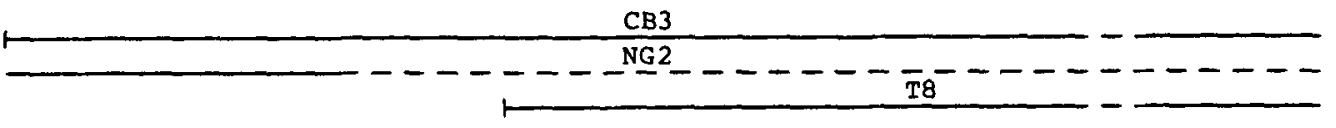

130

140

150

160

I S G D ${ }^{+} R$ T A H D S Y A F L A A W F E R F P H Y K R R E F Y V A G E S Y A G H

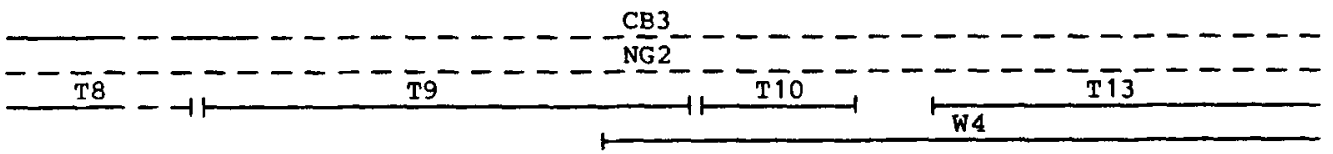

170

180

190

200

Y V P E L S Q L V H R S G N P V I N L K G F M V G N G L I D D Y H - - - - - - - $\frac{\mathrm{CB} 3}{\mathrm{~N} G \overline{2}}-------1 \longmapsto \quad \mathrm{CB} 4$

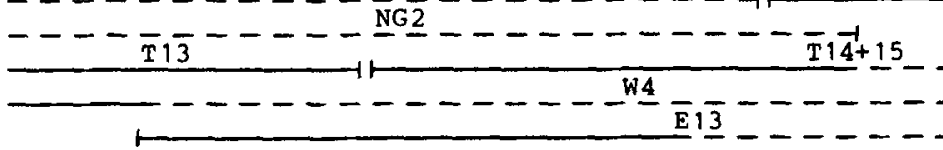

210220

230

240

FW WNH G I V S D D T Y R R L K D A C L H D S F I H P S P A C D A A T CB 4

\begin{tabular}{|c|c|}
\hline$---14 \pm 15----1$ & $\mathrm{~T} 17+18$ \\
\hline
\end{tabular}

$$
250
$$

260

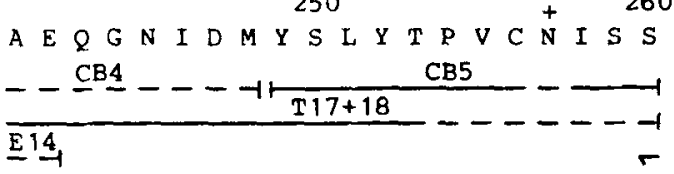

Figure 9. Amino acid sequence of the A-chain of malt carboxypeptidase II. Peptides were sequenced by automated Edman degradation (full line) and digestion with malt carboxypeptidase II (-). Each peptide fragment is indicated by a full line for sequenced residues followed by a broken line for residues not sequenced in that particular fragment. Peptide fragments are designated by the following nomenclature: CB, cyanogen bromide fragments; NG, hydroxylamine fragments; $T$, tryptic fragments; $E, S$. aureus V8 protease fragments; W, iodosobenzoic acid fragments. $\stackrel{+}{N}$ are glycosylated asparagines. 


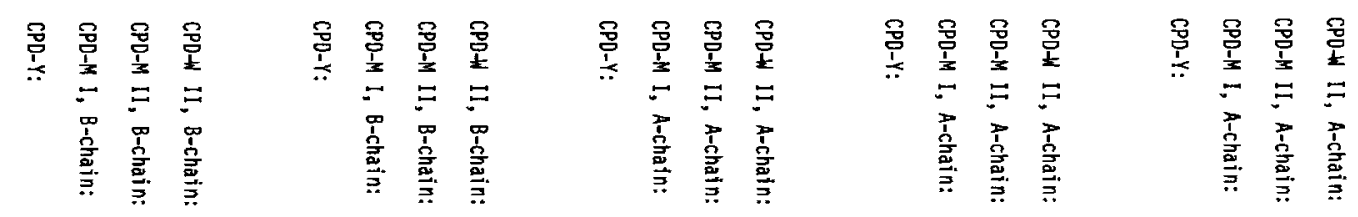

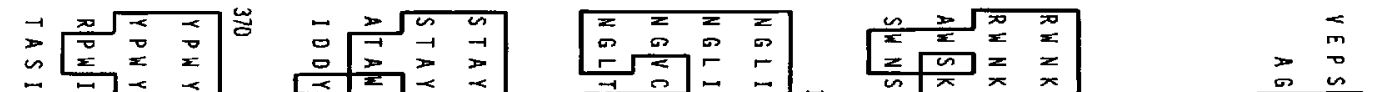

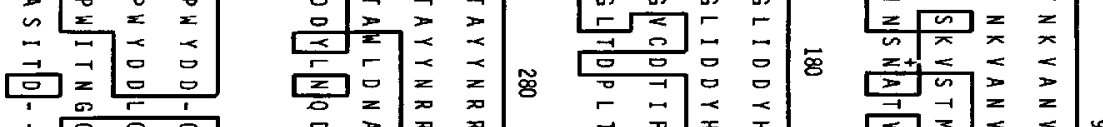

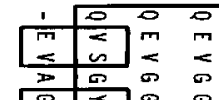

$\begin{array}{lll}\pi & a & a\end{array}$

\begin{tabular}{ll|ll}
$\pi$ & $\vec{m}$ & $=$ & $=$ \\
$\pi$ & $\pi$ & 0 & 0
\end{tabular}

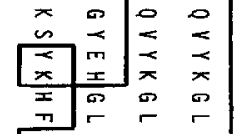

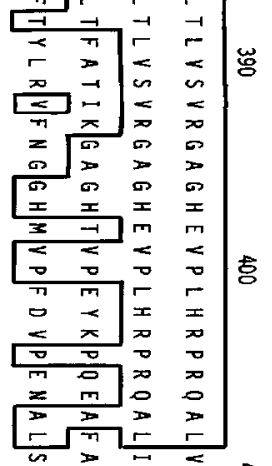

$=\pi\left[\begin{array}{ll}r & r \\ \pi & \pi \\ 0 & 0\end{array}\right]$

$=0$

$\begin{array}{lll}= & \pi & \pi \\ r & \sigma & 5\end{array}$

I 5 i

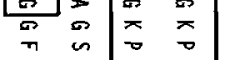

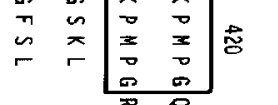

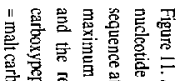

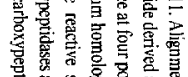

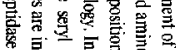

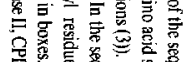

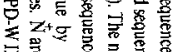

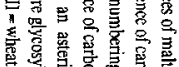

要

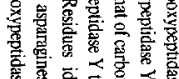

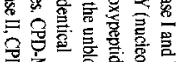

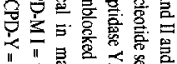

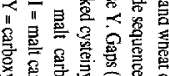

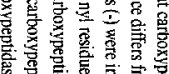

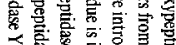

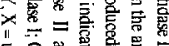

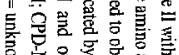

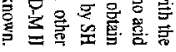

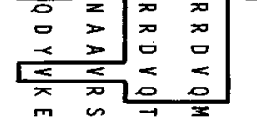

r

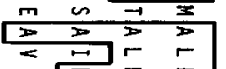

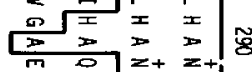

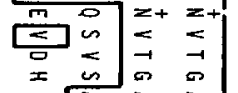

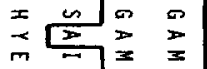

\begin{tabular}{ll|l}
$m$ & 5 & $z$ \\
$s$ & 0 & $z$ \\
$s$ & 0 & $z$
\end{tabular}

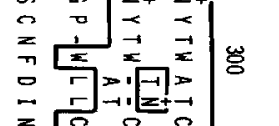

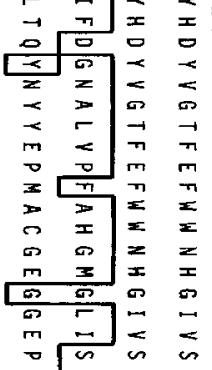

$\begin{array}{ccc}0 & n & 0 \\ 0 & 0 & 0 \\ 0 & 0 & 0 \\ 0 & 0 & 0\end{array}$

z r

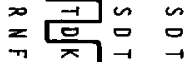

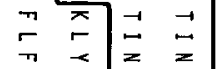

$\because \quad \begin{array}{lll}\pi & z & z \\ 1 & 1 & \pm\end{array}$

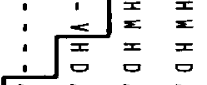

$\begin{array}{llll}1 & 0 \\ 5 & 0 & 5 & 0 \\ 0 & 0 & 0 \\ 0 & 1 & 0 & 0 \\ 0 & 0 & 0\end{array}$

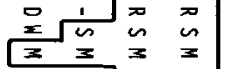

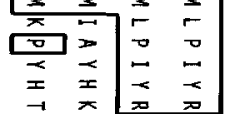

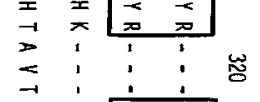

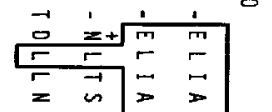

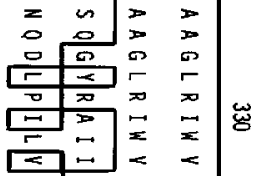

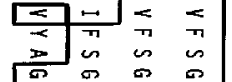

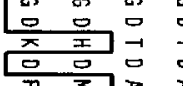

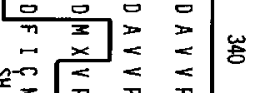

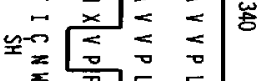

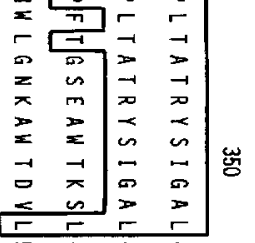

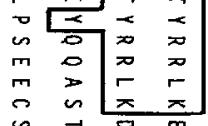

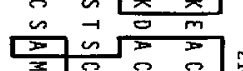

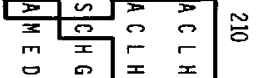

\begin{tabular}{ll|ll}
$m$ & $\mathbf{x}$ & $x$ & $x$ \\
0 & 2 & $x$ & 0 \\
0 & 0 & 0 & 0
\end{tabular}

$\begin{array}{llll}r & \vdots & n & 0 \\ m & n\end{array}$

$x$

$x \quad z+$

\begin{tabular}{ll|ll}
5 & -1 & $x$ & $x$ \\
0 & 0 & 0 & 0 \\
0 & 0 & 0
\end{tabular}

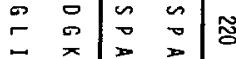

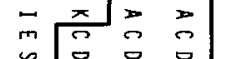

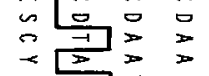

$\begin{array}{lll}2 & 2 \\ 0 & 7 & 2 \\ 0 & 0\end{array}$

$\begin{array}{llll}0 & 0 & 0 & 0 \\ 0 & 0 & 0 & 0\end{array}$

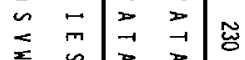

$=$ is $>>$

$\begin{array}{llll}5 & 5 & m & m \\ 0 & 0 & 0 \\ 0 & 0 & 0\end{array}$

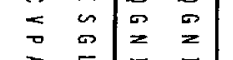

$\stackrel{1}{\rightarrow}$

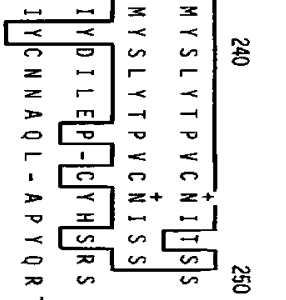

웅 웡

$2 \frac{1}{1} \frac{1}{3}$

$=5$

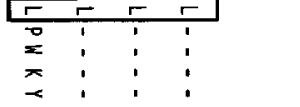

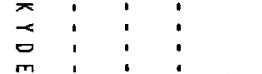

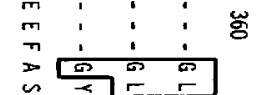

का

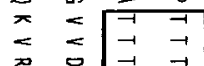

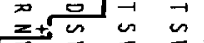

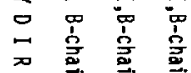

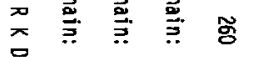

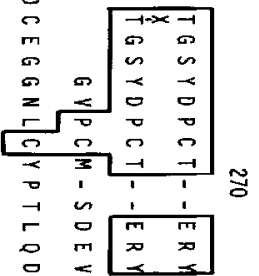

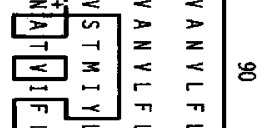

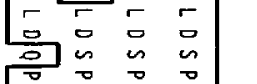

요인

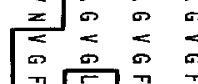

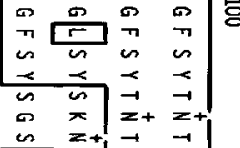

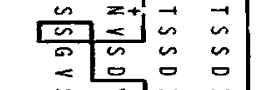

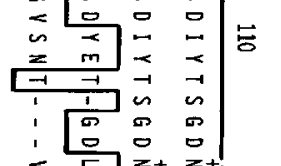

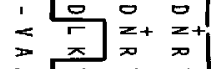

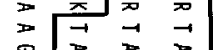

다물

$\sum_{-1}^{\infty}=\frac{1}{2}=$

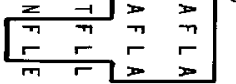

mix

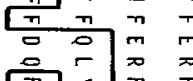

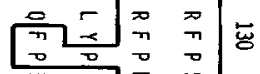

$\stackrel{m}{m}\left[\begin{array}{ll}x & x \\ x & x\end{array}\right.$

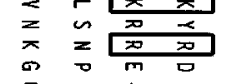

0 .

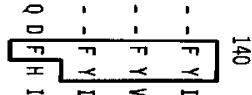

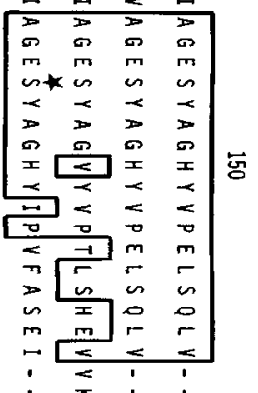

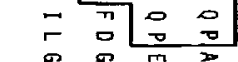

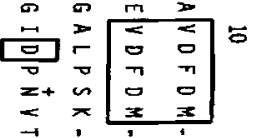

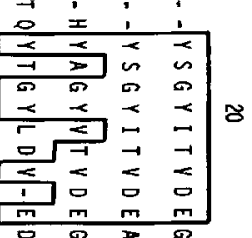

i m

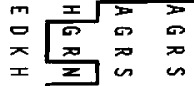

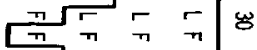

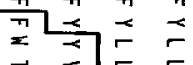

$\pi \leq 5$

m

$=m\left[\begin{array}{ll}m & 0 \\ = & m\end{array}\right.$

마에 0

$\therefore=0$

$\begin{array}{llll}\pi & \pi & 0 \\ 0 & 0 & 0\end{array}$

\begin{tabular}{lll}
\hline & 0 \\
\hline & 0
\end{tabular}

r $\leqslant \leqslant$

$\begin{array}{llll}z & z & z & z \\ r & r & r & z \\ z & z & z & z\end{array}$

$z z=z$

$\begin{array}{llll}0 & 0 \\ 0 & 0 & 0 & 0 \\ 0 & 0 & 0 & 0\end{array}$

$\begin{array}{llll}5 & 0 & \square & 0 \\ 0 & 0 & 0 & 0\end{array}$

$\therefore$ क 50

$\therefore$ is is is

50755

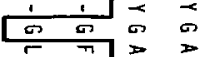

त 2 in in

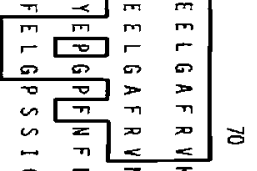

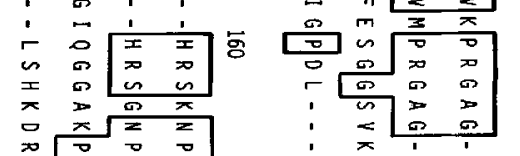

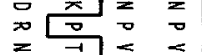

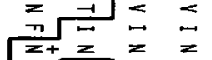

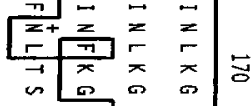

$\begin{array}{lll}5 & 5 \\ 5 & 3 & 3 \\ \square & 3 & 3\end{array}$

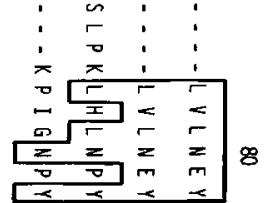




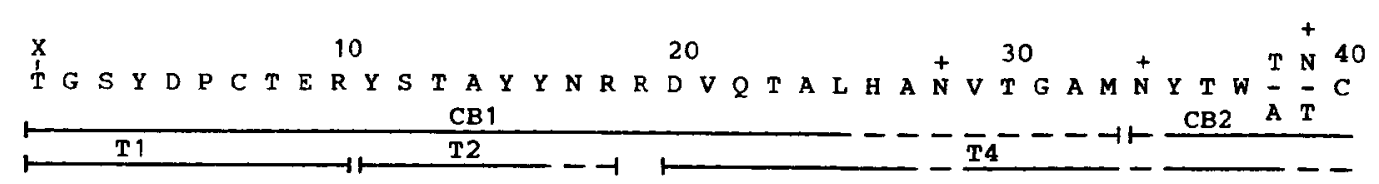

S D T I N T H W H D A P R S M L P I Y R E L I A A G L R I W V F S G D T D A V V CB2

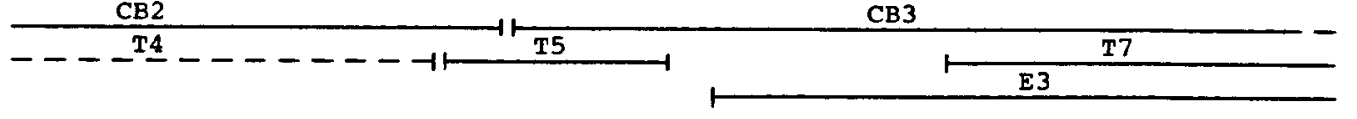

Figure 10. Amino acid sequence of the B-chain of malt carboxypeptidase II. Polymorphism is seen in position 38 and 39. $\mathrm{X}$ is the N-terminal blocking group. See legend for Figure 9.

sites in the the B-chain are asparagines $28,34,39$ and 159 , position 39 only in the form of the B-chain with Asn at position 39. No unused $\mathrm{N}$-glycosylation sites were found. The presence of glycosylated asparagine as C-terminal amino acid residue in the $B$-chain is unusual since the condition of glycosylation, i.e. a hydroxyamino acid residue two positions in the C-terminal direction, is not fulfilled. This implicates a proteolytic processing subsequent to glycosylation. This position of the carbohydrate moiety is consistent with the lack of released amino acids by digestion with carboxypeptidase $\mathrm{Y}$.

Each subunit of the enzyme contains 6 cysteinyl residues consistent with the presence of 3 disulphide bridges. Like in wheat carboxypeptidase II, but unlike carboxypeptidase $Y$ and malt carboxypeptidase I, no free sulphydryl group is present.

Comparison of the amino acid sequence of malt carboxypeptidase II with those of other proteins only demonstrated homology with malt carboxypeptidase I, wheat carboxypeptidase II and carboxypeptidase $\mathrm{Y}$. The alignment, with due allowance for gaps, of the amino acid sequences of these four serine carboxypeptidases is shown in Figure 11. The A-chains of the cereal carboxypeptidases show regions of high homology with the N-terminal part of carboxypeptidase Y (Figure 11). Similarly, the B-chains of the cereal carboxypeptidases show homology with the C-terminal part of carboxypeptidase $Y$. The percentages of homology are shown in Table II. The sequences of malt carboxypeptidase II and wheat carboxypeptidase II are almost identical (95-96\% homology) suggesting that they are functionally equivalent. The homology with malt carboxypeptidase $I$ is significantly lower but it is higher than that with carboxypeptidase Y (see Table II). This indicates, as would be expected, that the three cereal carboxypeptidases mutually are more closely related than each of 
Table I. Amino acid composition of A- and B-chains of malt carboxypeptidase II

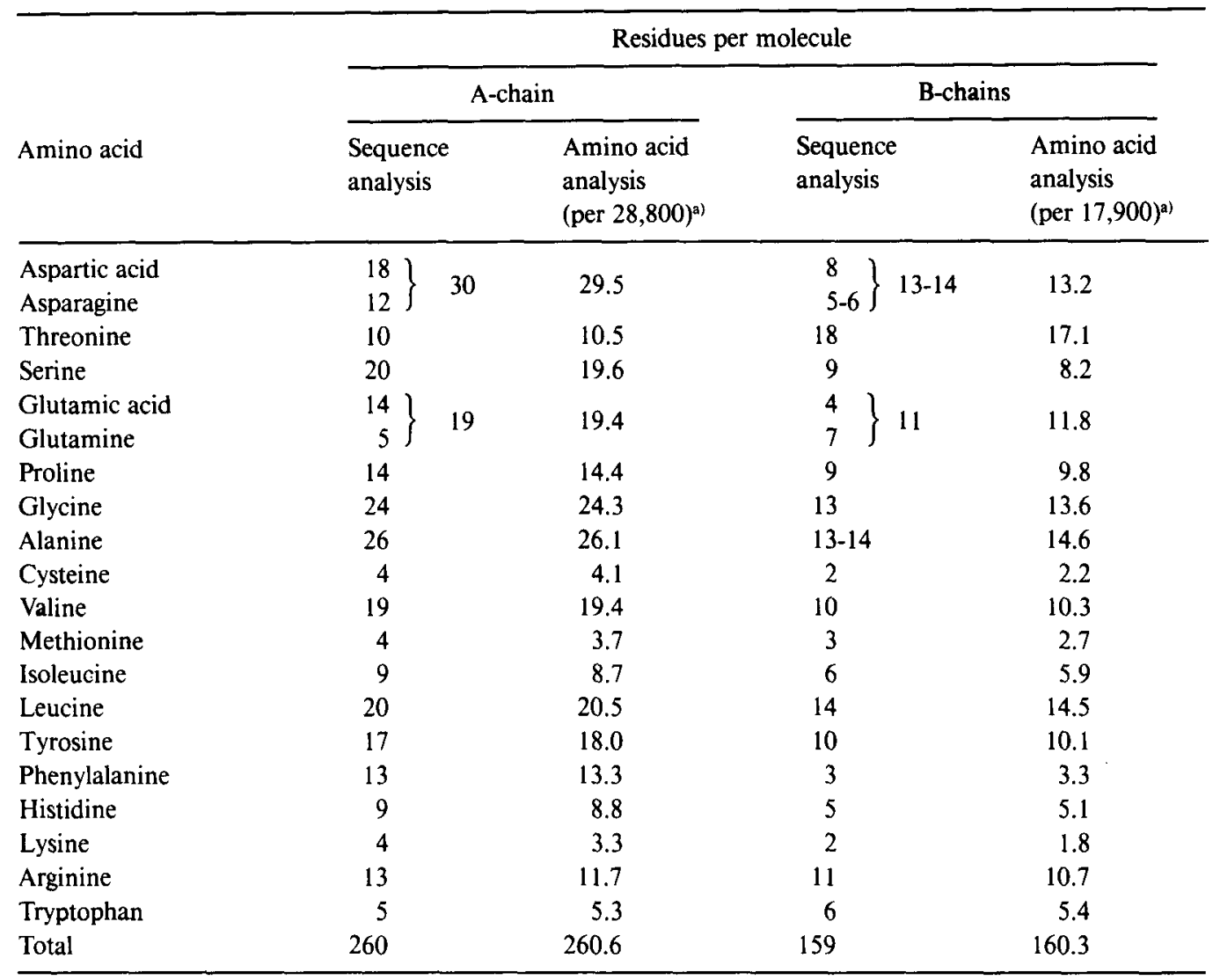

a) Based on the calculated mol.wt. of the protein part.

them is related to carboxypeptidase $Y$.

Two regions in the four enzymes are highly conserved, i.e. the regions 48-58 and 143-149 in the carboxypeptidase $Y$ numbering. The essential $\mathrm{Ser}^{146}$ of carboxypeptidase $Y(10)$ is located in the latter region and the conservation of this residue in all four carboxypeptidases suggests that it is the active site serine in these enzymes as well. The sequence around the reactive seryl residue in three serine carboxypeptidases from citrus fruits $(9,15)$ exhibit higher homology with the corresponding regions of serine endopeptidases like trypsin, chymotrypsin, elastase and plasmin than the cereal carboxypeptidases and carboxypeptidase $Y$. This supports the earlier suggestion (18) that two separate groups of plant serine carboxypeptidases exist.

The conserved region $48-58$ is not present in the serine endopeptidases and it does not contain aspartic acid or histidine, indicating that it is not a part of the catalytic triad in the active site (1). However, the presence of three glycyl and one prolyl residue in this region suggest a highly twisted peptide chain most reasonably important for the three-dimensional structure of the enzymes. This is consistent with the presence of Cys in position 56, which participates in an S-S bridge with another Cys-residue in the molecule.

Earlier indications that $\mathrm{His}^{397}$ is the most probable candidate to the histidyl residue functioning as an acid/base catalyst in the active site (18) is supported from this histidine being the only histidine conserved in all four enzymes.

It is not clear which of the aspartic acid residues participate in the active site, since five aspartic acid residues are conserved in all four 
S.B. SøRENSEN et al.: Sequence of malt carboxypeptidase II

Table II. Amino acid sequence homolgy (\%) between serine carboxypeptidases

\begin{tabular}{|c|c|c|c|}
\hline Peptide chain & $\begin{array}{l}\text { A-chain CPD-M II } \\
\text { ( } 260 \text { residues) }\end{array}$ & $\begin{array}{l}\text { A-chain CPD-W II } \\
\text { ( } 263 \text { residues) }\end{array}$ & $\begin{array}{l}\text { A-chain CPD-M I } \\
\text { (266 residues) }\end{array}$ \\
\hline A-chain CPD-W II & 95 & & \\
\hline A-chain CPD-M I & 40 & 41 & \\
\hline CPD-Y (421 residues) & 28 & 29 & 29 \\
\hline Peptide chain & $\begin{array}{l}\text { B-chain CPD-M II } \\
\text { (159 residues) }\end{array}$ & $\begin{array}{l}\text { B-chain CPD-W II } \\
\text { (160 residues) }\end{array}$ & $\begin{array}{l}\text { B-chain CPD-M I } \\
\text { (148 residues) }\end{array}$ \\
\hline B-chain CPD-W II & 96 & & \\
\hline B-chain CPD-M I & 30 & 30 & \\
\hline CPD-Y (421 residues) & 21 & 21 & 24 \\
\hline \multicolumn{4}{|c|}{$\begin{array}{l}\text { CPD-M I }=\text { malt carboxypeptidase } \mathrm{I} \\
\text { CPD-M II }=\text { malt carboxypeptidase } \mathrm{II} \\
\text { CPD-W II }=\text { wheat carboxypeptidase II } \\
\text { CPD-Y }=\text { carboxypeptidase } \mathrm{Y}\end{array}$} \\
\hline
\end{tabular}

enzymes. However, $\mathrm{Asp}^{94}$ may be the most probable candidate because it is situated in a region, which is rather well conserved.

\section{ACKNOWLEDGEMENTS}

We are grateful to Professor MARTIN OTTESEN for helpful discussions during all stages of this work and a critical revision of the manuscript.

The authors wish to acknowledge Mss. LILlian AbildgaArd, Susanne Evald and $\mathrm{Mr}$. THORKILD BEENFELDT for excellent technical assistence with preparation of enzyme and fragments thereof and Mss. PIA BREDDAM, BoDIL Corneliussen and Lone Sørensen for the amino acid analyses and sequencing.

\section{REFERENCES}

1. BACHOVCHIN, W. W. \& J. D. RoBeRTS: Nitrogen-15 nuclear magnetic resonance spectroscopy. The state of histidine in the catalytic triad of $\alpha$-lytic protease. Implications for the charge-relay mechanism of peptide-bond cleavage by serine proteases. J. Am. Chem. Soc. 100, 8041-8047 (1978)

2. BREDDAM. K.: Serine carboxypeptidases. A review, Carlsberg Res. Commun. 51, 83-128 (1986)

3. BREDDAM, K. \& I. SVEndSEN: Identification of methionyl and cysteinyl residues in the substrate binding site of carboxypeptidase Y. Carlsberg Res. Commun. 49, 639-645 (1984)

4. BREdDam. K. \& S. B. Sørensen: Isolation of carboxypeptidase III from malted barley by affinity chromatography. Carlsberg Res. Commun. 52, 275-283 (1987)

5. BREDDAM. K.. S. B. SøRenSEn \& M. OtTeSEN: Isolation of a carboxypeptidase from malted barley by affinity chromatography. Carlsberg Res. Commun. 48, 217-230 (1983)

6. BREDdam. K.. S. B. SøRenSEn \& M. OTtesen: Isolation of carboxypeptidase II from malted barley by affinity chromatography. Carlsberg Res. Commun. 50, 199-209 (1985)

7. Breddam, K. S. B. Sørensen \& I. Svendsen: Ptimary structure and enzymatic properties of carboxypeptidase Il from wheat bran. Carlsberg Res. Commun. 52, 297-311 (1987)

8. Fontana. A.. D. Dalzoppo. C. Grandi \& M. ZamBONIN: Cleavage at tryptophan with o-iodosobenzoic acid. Meth. Enzymol. 91, 311-318 (1983)

9. Funakoshi. T. S. Shoj, R. Yokoyama. H. Ueki \& Y. KUBOTA: The active site of carboxypeptidase $\mathrm{C}_{\mathrm{U}}$. I. Evidence for serine in the active sites of carboxypeptidases $\mathrm{C}_{\mathrm{Ua}}$ and $\mathrm{C}_{\mathrm{Ub}}$. Chem. Pharm. Bull. 31, 198-203 (1983)

10. Hayashi. R. S. Moore \& W. H. Stein: Serine at the active center of yeast carboxypeptidase. J. Biol. Chem. 248, 8366-8369 (1973)

11. Houmard, J. \& G. R. Drapeau: Staphylococcal protease: A proteolytic enzyme specific for glutamoyl bonds. Proc. Natl. Acad. Sci. U. S. A. 69, 3506-3509 (1972) 
12. Johansen. J. T., C. Overballe-Petersen, B. Martin, V. Hasemann \& I. SVEndsen: The complete amino acid sequence of copper, zinc superoxide dismutase from Saccharomyces cerevisiae. Carlsberg Res. Commun. 44, 201-217 (1979)

13. Martin, B. M.., I. Svendsen, T. Viswanatha \& J. T. JOHANSEN: Amino acid sequence of carboxypeptidase $Y$. I. Peptides from cleavage with cyanogen bromide. Carlsberg Res. Commun. 47, 1-13(1982)

14. MiKOLA, L:: Germinating barley grains contain five acid carboxypeptidases with complementary substrate specificities. Biochim. Biophys. Acta 747, 241-252 (1983)

15. Shoji. S.. S. Narimatsu. T. Morita. T. Funakoshi. H. UEKI \& Y. KUBOTA: The structure and function of carboxypeptidase $\mathrm{C}_{\mathrm{N}}$. Chem. Pharm. Bull. 33, 4963-4972 (1985)

16. SVENDSEN, I., B. MaRTIN \& I. Jonassen: Characteristics of Hiproly barley. III Amino acid sequences of two lysine-rich proteins. Carlsberg Res. Commun. 45, 79-85 (1980)

17. Svendsen, I., B. M. Martin. T. Viswanatha \& J. T. JOHANSEN: Amino acid sequence of carboxypeptidase Y. II. Peptides from enzymatic cleavages. Carlsberg Res. Commun. 47, 15-27 (1982)

18. Sørensen. S. B.. K. BReddam \& I. Svendsen: Primary structure of carboxypeptidase I from malted barley. Carlsberg Res. Commun. 51, 475-485 (1986)

Accepted by H. KLENOw 